\title{
Interactive Research on Innovations in Vocational Education and Training (VET): Lessons from Dutch and German cases
}

\author{
Joanna Burchert* \\ University of Bremen \\ Institute of Technology and Education (ITB) \\ Am Fallturm 1, 28359, Bremen, Germany \\ E-mail: burchert@uni-bremen.de
}

\author{
Aimée Hoeve \\ HAN University of Applied Sciences \\ Research Centre for Quality of Learning \\ P.O. Box 30011, 6503 HN Nijmegen, The Netherlands \\ E-mail: aimee.hoeve@han.nl \\ Pekka Kämäräinen \\ University of Bremen \\ Institute of Technology and Education (ITB) \\ Am Fallturm 1, 28359, Bremen, Germany \\ E-mail: pkamar@uni-bremen.de \\ * Corresponding author
}

Received: 15 July 2014; Accepted: 15 October 2014; Published online: 30 December 2014

\begin{abstract}
This article focuses on two examples of interactive research (IR) in vocational education and training. IR is a process which brings together practitioners and researchers with the aim to implement an innovation. This innovation in the first project meant to create a hybrid learning environment; in the second it supported introducing digital media in a training centre. The process of innovating thereby turned into a learning process for all concerned persons: original ideas of the concerned concepts matured, boundaries between research and practice were crossed and new, sometimes surprising ideas for further development emanated. These experiences point attention towards the processes of research and innovation instead of only documenting results in the sense of summative evaluation. They also show that IR requires a certain framework in order to enable important learning cycles.
\end{abstract}

Keywords: interactive research, collaborative research, cooperation of learning venues, information and communication technology 


\section{Bibliographical notes:}

Aimée Hoeve is senior researcher at Research Centre Quality of Learning of the HAN University of Applied Sciences in The Netherlands. Her research interests focus on workplace learning, vocational expertise, design of hybrid learning environments and co-makership VET and business partners.

Pekka Kämäräinen and Joanna Burchert are senior researchers at the Institute of Technology and Education (ITB) at the University of Bremen, Germany. Three of their research interests are workplace learning, the use of digital media in VET and the work of trainers and teachers in VET. 


\section{Introduction}

This article provides insights into interactive research in the field of vocational education and training (VET). As interactive research we define cooperation between practitioners and researchers with the goal to implement new, useful and significant changes in the practice which also aim to enrich the state of research (see below). We want to illustrate this approach and its outcomes in two contexts: The Dutch contribution is based on a national programme for promoting work process oriented innovations in the Dutch secondary vocational education - the aim of the here referred project was to merge work-related learning and learning in school-based settings. The German contribution is based on an EU-funded project which invents mobile learning tools to support learning at the workplace. As example, we describe how a German industry-supported intermediate training centre in the construction sector implemented digital media as a holistic institutional innovation.

The background for the cooperation of these articles' authors was laid down at the ECER 2013 conference in Istanbul when the Dutch researchers organised a research workshop to analyse the use of interactive research approaches (for the conceptual background of interactive research, see Ellström 2008, 2010 and Akkerman et. al., 2013; for the project cases see Nieuwenhuis et al., 2012 and Zitter and Hoeve, 2012).

This article presents firstly the idea of interactive research, then its contexts and reference cases in the Netherlands and in Germany. After this, the research designs of the interactive projects are discussed. The last section presents a comparative overview and draws conclusions for further development of interactive research and development projects.

\section{Interactive research as a concept}

Interactive research is one form of collaborative research: it is a process which brings together practitioners and researchers. Ellström (2007) defines interactive research as a research position "in contrast to traditional academic research on the one hand and action research on the other hand” (p. 2). This means that interactive research aims at breaking traditional boundaries between research and practice, but also to strengthen the role of research and reflection in collaborative development processes (the lack of conceptual and theoretical development is from Ellströms point of view the basic critique on many variants of action research). Ellström (2007, 2008, 2010) points out that interactive research should contribute to the two tasks of addressing practical concerns and the creation of scientifically valid knowledge, such as new concepts, theories and models. Additionally, a third task needs to be included, namely the educative task of developing and enriching the knowledge and competencies of the parties involved through individual and collective learning. Ellström argues that this third task is conditional to accomplishing the other two tasks. Therefore interactive research is essentially about the joint learning process of practitioners and researchers.

A further basic idea underlying interactive research is its emphasis on knowledge creation through an egalitarian co-development between researchers and practitioners with a focus on a shared problem or research object. The processes in the two interacting systems, namely, the research system and the practice system, are viewed as cyclical in character and driven by problems or issues originating in research or practice. Ideally, these two activity systems may be seen as interlocked, 
collective learning cycles that produce successive versions of shared conceptualizations of the research object.

In contemporary Dutch and since the 1970s in the German education, particularly in vocational education, many innovation projects take place in which research is incorporated (see Rauner and Oehlke, 2008; Sloane, 2008; Rauner and Maclean, 2008; Deitmer, 2004; Deitmer et al., 2004). In the German research, the typical form of cooperation on the research site was referred to as "accompanying research", and co-design, support and evaluation were regarded as its core ideas. However, there are no clear-cut answers about the interaction between such research and innovation yet: the interplay between knowledge creation and innovation therefore is an important issue of our research. Researchers and practitioners are assumed to co-produce shared knowledge and understanding of the research object through joint exploration and analysis of data - but mutual conceptual development does not take place automatically (Akkerman et al., 2013; Stokols, 2006). The socio-cultural differences between the research and practice systems may give rise to discontinuities in interaction and action, in which case participants are faced with boundaries. Though facing boundaries can prove challenging, boundaries also have learning potential. Akkerman and Bakker (2011) identified four different types of boundary practices:

(a) Coming to know what the diverse practices are about in relation to one another;

(b) Creating cooperative and routinized exchanges between practices;

(c) Expanding one's perspectives on the practices;

(d) Collaboration and co-development of (new) practices.

Interactive research often takes place in the context of innovation processes that are aimed to have a wider scope than single pilot cases. In this respect the article studies innovations in education and training that are supposed to have an impact on learning in working life. This working perspective brings into picture a wider range of partner organisations and networks.

The focus on educational innovation means - in contrast e.g. to more economic perspectives - that the innovations aspired are not new for the world, but new for the institution which implements them. This implies that the focus is not so strong on invention, but on adaptation of ideas and their implementation strategies (Burchert 2010). Both projects discussed in this article chose challenging fields of innovation:

- The Dutch case aims at supporting hybrid learning environments. Such cooperation between learning venues can only be based on cooperativeness and thoughtful pedagogical concepts. The problem is, that there are not many good practice examples for this even in a country with a long tradition of dual education like Germany (Euler and Berger, 1999);

- In the German case, the implementation of digital media in the education context is in focus. This innovation bears the challenge to combine technology and didactic in a thoughtful way. Mobile technology, it is argued, allows and supports learning in informal contexts. Nonetheless, in formal contexts, no significant effects for the use of digital tools or the web 2.0 are stated until now (see e.g. www.nosignificantdifference.org).

So in both projects, a great deal of uncertainty was standing at the beginning, turning the cooperation of research and practice into a learning journey. In the next 
chapters we describe the project contexts, how interactive research took place therein and what was learned by this form of cooperation.

\section{The Dutch project "Hybrid learning environments"}

\subsection{The research context}

Vocational education and training (VET) plays a central role in preparing young people for work, for developing adequate skills and responding to the labourmarket needs of the economy. The transition which learners are required to make from education to the workplace is a complex and often problematic process (Tynjälä et al., 2003). Studies show a gap between what is learned and what is required of competent professionals in an ever more complex world (Baartman and De Bruijn, 2011). The integration of students' learning experiences across academic and practice settings is currently of considerable interest within the educational sectors in a number of countries (Billett, 2011), among which the Netherlands. The last decade Dutch VET institutes have been experimenting to design learning environments that cross the traditional school boundaries into working life (Zitter and Hoeve, 2012). One of these projects was "Hybrid learning environments" which shows how school-based learning and workplace experiences can be closely connected to deal with problematic transitions between education and the workplace.

This project ${ }^{1}$ was based on cooperation between the National Centre for Expertise in Vocational Education and Training (ecbo), two Dutch Secondary Vocational Educational institutions, one Higher Vocational Educational Institute and their business partners. The sectors were hospitality industry and the building and construction industry. The partners of the joined projects signed up because they embrace the dual goals of the projects: educational innovation combined with practice-based research. The research part aimed at revealing the underlying design principles of a hybrid learning environment. The focus in design research is to show how the concept of hybrid learning environments is translated into practice in a certain context, whether the outcomes in that context are realised and, if possible, due to which mechanisms that are presupposed by the designers (Van Aken and Andriessen, 2011). The national Centre for Expertise in Vocational Education and Training is responsible for the research aligned with this project. The research consists of the following types of research activities:

- Systematic reflection by practitioners;

- Localized research by practitioners-researchers;

- Applied research by scientific researchers.

An exploratory field study (Huisman et al., 2010) uncovered a variety of forms of hybrid learning environments already present in Dutch vocational education. On the basis of this exploratory study, the collaborative partners of the multistakeholder, multiannual educational innovation and research project were found.

The project "Hybride leeromgevingen in het middelbaar beroepsonderwijs [Hybrid learning Environments in Dutch VET]" was funded by ecbo (Centre for Expertise in Vocational Education) from 2010-2013. See http://www.ecbo.nl/7_1644_Hybrideleeromgevingen.aspx. 
The project ran from May 2010 until the December 2013. It can be characterized as a design-oriented, applied research project from the Centre for Expertise in Vocational Education (ecbo-project) and an educational innovation/ practitionerresearch project (hpbo-project).

\subsection{Innovation, crossing boundaries and lessons learned}

In the last decade Dutch VET institutes have been experimenting to design learning environments that cross the traditional school boundaries into working life. Zitter (2010) introduced the term hybrid learning environments as follows: "A learning environment can be considered as a 'hybrid learning environment" when different formal and informal elements are woven together into coherent programmes of learning and into single learning environments, rather than a programme that combines different components with the aim of offering a more enticing menu of learning for the students" (Zitter and Hoeve, 2012 in OECD 2013, p. 138).

Within the project, hybrid learning environments were (re)designed and implemented at two different sites in two domains:

- In the hospitality industry, there is a complete turnover of the curricula of the programmes involved, team teaching is introduced and the teachers develop from monoprofessionals to multiprofessionals. This change can be characterized as a multi-level approach.

- In the building and construction industry, integration of a hybrid learning environment into the current curricula took place, which included cooperation between secondary and higher vocational education and also a transfer from monoprofessional to a multiprofessional teaching approach.

The (re)design towards a hybrid learning environment was conceptually based on the Hybrid Framework (Zitter and Hoeve, 2012). The Hybrid Framework consists of two dimensions, see figure 1.

The first dimension has on one side the knowledge acquisition metaphor, in which knowledge is considered as a commodity that can be acquired, transferred and shared with others. On the other side is the participation metaphor, characterising learning as becoming a member of a professional community. The second dimension is constructed-realistic: it characterises how realistic learning tasks are. Constructed settings are characterised as low-fidelity: the rich reality of society, and specifically of professional practice, is reconstructed. Moving towards the realistic-side of this dimension, constructed settings can become of higher fidelity, for example, by involving simulation technology, internal employees or outside actors to enact roles like client or patient. Moving to the right-hand side of the dimension are realistic settings that closely mirror the real professional context; learners may be situated in an actual, real-world workplace setting. 


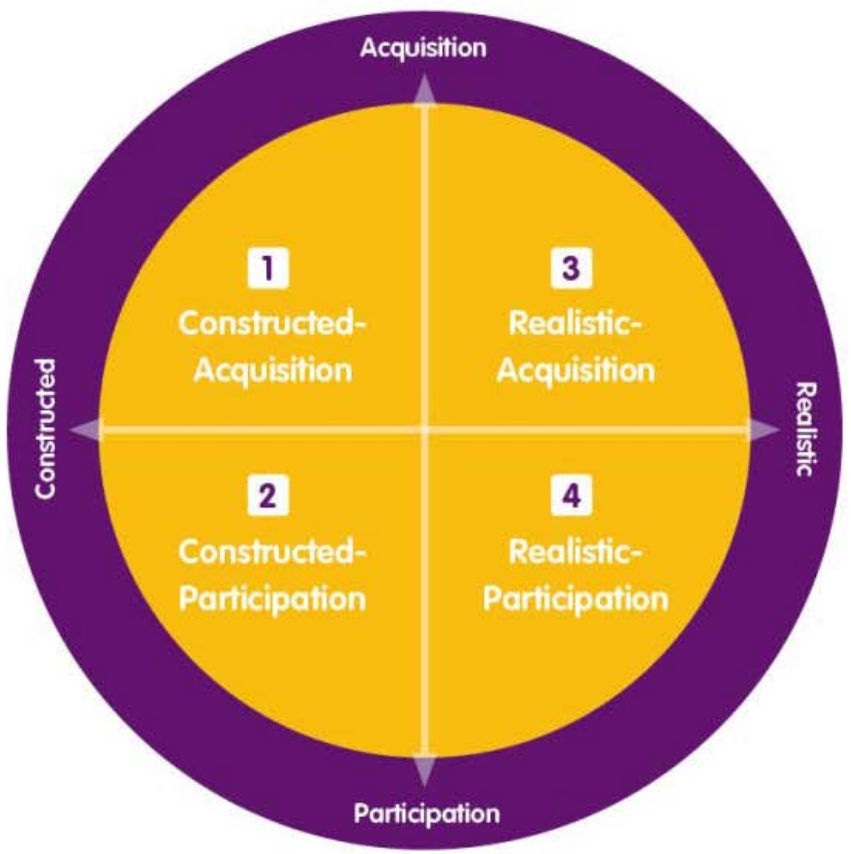

Figure 1: Two dimensions and four quadrants (Zitter and Hoeve, 2012)

These two dimensions form four quadrants, each with specific types of situations. For example, classic lectures to present explicit theoretical knowledge fit in the constructed-acquisition quadrant. Discussing or presenting work experiences to enable tacit knowledge to be made explicit fit in the realistic-acquisition quadrant. Group assignments or simulations go in the constructed-participation quadrant. In the realistic-participation quadrant are the most realistic situations, such as working for actual, external clients from within a school-based setting, as well as working side-by-side with professionals in real-life workplaces. In a hybrid learning environment all quadrants should be represented and need to be aligned with each other.

Designing a hybrid learning environment is not an easy endeavour (Zitter and Hoeve, 2012). It requires long term commitment of both parties, i.e. VET-institutes and business partners, to develop new forms of integrating learning and working processes. To ensure long term commitment, including suitable funding, a syndicate was formed consisting of different partners from senior secondary education, higher education and business partners from local trade and industry. In this process it was necessary to delineate the roles of the partners. The potential partners each had different research agendas, different future visions of the needed educational redesign and were at different stages in the educational change process.

Forming a syndicate can be interpreted a process of identification, creating routines of exchange, expanding one's practices and transformation. Identification means coming to know what the diverse practices are about in relation to one another. Noteworthy in this process of identification is the vision of the different partners on research. At the start of the project, the educational partners had classic ideas about research as a neutral and distant process leading to theoretically interesting outcomes with little value for direct application in practice. In contrast, 
the researchers from the research institute worked from a different research paradigm in which research is of highly collaborative nature. By taking collaborative action these differences were overcome. An example of collaborative research action is co-observation of two pilot studies in which initial re-designs of hybrid learning environment were tested.

The next learning mechanism to be identified in this project entails the effort of translation between the different worlds to create cooperative and routinized exchanges between practices, i.e. coordination. In this project a conceptual model was used that was developed in a PhD-research project (Zitter, 2010). But during the process, this conceptual model transformed in different forms and incarnations to suit the developing practices. It emerged from a scientific format to a storyboard model and to an animated version. Where the initial model was suitable for scientific publications, the storyboard model helped to validate observations and analysis with the participants in the project. Using photographs from daily practice at the project sites helps to translate daily situations to systematic analysis using scientific models and vice versa. The animated version helps to communicate the design principles of hybrid learning environments with other contexts (outside the project).

The third learning mechanism is reflective in nature: to expand one's perspectives on the practices. In this project, we applied the 'critical moments reflection methodology', a semi-structured, reflective group-interview with the different partners involved (educational change, design and research). All partners are asked to list the critical moments of a set time period. These critical moments are placed on a timeline and briefly addressed which helps to build collective understanding of developments. The participant choose from a selection of moments which moments they want to reflect on; by discussing these moments indepth underlying assumptions, implicit decisions, lessons learned are made explicit.

The last learning mechanism is transformation, i.e. collaboration and codevelopment of new practices. On the first project site a hybrid learning environment in action was realized. The process of developing this hybrid learning environment can be considered as a collaborative effort of research and practice. It is neither a research project nor a educational change project but a blend of design, research and change with improving educational practice as a shared purpose.

Further, the hybrid learning environment in itself can be considered as a transformative form in which ingredients of different contexts are combined in something new and unfamiliar. In hybrid learning environments forms of formal schoolbased and informal work-based learning cross fertilize in a new form of vocational education.

\subsection{Reflective commentary}

In this project, many established boundaries were crossed: the boundary between research and practice, the boundary between applied research and more fundamental PhD-research, the boundaries between educational institutes and business, the boundary between different types of organisations. All participants come from different worlds and bring in their own goals, their own language, their own culture, and so on. Sustained collaboration across these boundaries is a challenging process, which takes time and considerable effort from the partners involved. But the boundaries entail also a high learning potential. In this project we can expose the four types of boundary practices that are identified by Akkerman and Bakker (2011). In reflection on this project we experienced that the first is conditional, the 
second and third ensure meaningful exchange. The combination of type 1, 2 and 3 can lead to co-development of new practices. In this project this stage was reached in the context of the hospitality case. Important success factors to be identified in the hospitality case are:

- leadership;

- teamwork;

- broad curriculum perspective (broad ownership);

- systematic design process;

- scheduled design time;

- teacher-researchers active in the context.

Identification of the learning experiences in this case help future innovation projects to put the ideals of interactive research in practice. Forming a syndicate and not only negotiate interests but also roles, is helpful in the process of identification. Akkerman et al. (2013) distinguish and characterise three practices: a) educational research, b) educational design and c) educational change. Each practice represents a certain logic and dynamic. This framework can be used in the process of identification.

Adaptation of scientific models to local language and more dynamic formats can serve as a fruitful means of coordination. The 'critical moments reflection methodology' (Ferreira n.d.) can be used to trigger the mechanism of reflection. Both lead to regular meaningful interaction between the project partners. Finally, to reach transformation takes time and requires looking carefully at conditions such as leadership, broad ownership, scheduled time to work on innovation, and so on.

\section{The German case: "Bau-ABC goes web 2.0"}

\subsection{The research context}

The EU-funded Learning Layers project ${ }^{2}$ aims to develop a set of modular and flexible software for supporting workplace practices in small and medium sized enterprises (SMEs). These tools shall especially promote peer production of learning materials and aim to scaffold learning in networks of SMEs, which means to bridge the gap between institution-wide adaptation and the adaptation to personal needs. The Learning Layers tools want to integrate a meaningful learning context where people interact with people, digital and physical artefacts to support informal learning. The project is designed around mobile learning research, to situate learning in physical workplaces and practices to support easier access to information and thereby more meaningful learning. It addresses two sectors that have been particularly hesitant to take up learning technologies: the building and construction industry and health care. The Learning Layers project includes as partners representatives of regional SME clusters - building and construction in north west Germany and health care in Yorkshire UK, as well as research partners from five other European countries. Germany:

In this paper, we will focus on an example from the construction sector in

2 Learning Layers (http://learning-layers.eu/) is a large-scale research project co-funded by the European Commission's 7th Framework Programme as part of the ICT2011.8.1 Technology-Enhanced Learning call. It started 2012 and will end in 2016. 
- The practical partner is the Bau-ABC, a training centre which provides basic skills for apprentices in construction occupations as a service for companies. The role of the Bau-ABC is that of a multiplier: what apprentices learn here, they can (theoretically) as well apply at their work places;

- The research partners work at the Universities of Bremen and Karlsruhe and in design companies in the UK (additional research and design institutions from other countries were peripherally involved in the cooperation). The task of some research partners was to develop and to program tools (we refer to them as "designers"); other partners - like the authors of this article - were rather responsible for accompanying and evaluating the use of these tools from the perspective of vocational pedagogy.

The Bau-ABC's motivation to join the project was to develop Personal Learning Environments (PLEs) which are connected institution-wide and responsive to different contexts and processes of learning. Researchers and developers together with managers, trainers and apprentices from Bau-ABC work on this issue since October 2012 and will continue until October 2016. The idea to install a PLE is connected with the wish to improve learning processes, to find a better way of communicating with the young people and to stay competitive on the training market. The challenges of the process were and are:

- to formulate adequate technical ideas: this means e.g. not to change systems which work well paper-based or not to try to solve social problems in a technical way;

- to create tools which answer to those formulated problems: this means that researchers as developers of tools and practitioners as their users need to find a good communication base. This base requires from the researchers understanding of the practical context (education in the field of construction) and the practitioners need to understand the basic ideas of modern digital tools;

- to support institutional implementation of the developed tools: this means not only that the developed tools really need to fit to its needs, but also that certain resources and structures must be available (e.g. digital devices, a policy which allows to use mobile devices in the learning site etc.).

To assure the success of the project, the practitioners - trainers, managers and apprentices - were from the beginning involved in the design of the Learning Layers tools. This participative design idea (Burchert et al., 2013) brought into life a complex research and development process, in which pedagogic challenges and socio-technical design processes have got interlinked with each other. This will be described in the next chapter.

\subsection{Innovation, crossing boundaries and lessons learned}

The first ideas for tools which could be developed to support vocational learning derived from interviews, two-day visits at the Bau-ABC and design workshops with the trainers and with apprentices from Bau-ABC. Here it is important to see that research work is not merely a mapping exercise to prepare the grounds and needs for design process or an ex post evaluation of the usability and impact of the proposed tools, software solutions and web applications or services. Neither was the design process an isolated technical exercise that tries to find allegedly best 
solutions that meet the expectations that have been identified by analysing the empirical material produced by research. Instead, the dialogues and participative co-design workshops helped researchers, tool developers and Bau-ABC trainers to select specific domains and project areas for rapid prototyping and to develop some common ideas.

In this process, the first tool which the project wanted to develop gained the colourful name Sharing Turbine and aimed to digitalize the White Folder, a collection of working and learning tasks issued to all apprentices at the training centre Bau-ABC. The apprentices are asked to fill out this paper-based White Folder as documentation of their work and a cumulative learning log. Although this documentation could support the preparation for the final examinations which stand at the end of apprenticeship training in Germany, not every apprentice feels committed to use it. By digitalisation, we thought, we could reach such apprentices better. Although the design work to support the selected project areas with wireframes was seen as a good initial approach, it became apparent that elements of the White Folder tasks do not easily transfer into a mobile digital format per se. The aim of the project in developing an enhanced pedagogic approach would have led to an extremely time-consuming effort to digitalise all tasks in their existing form. It also became questionable whether the digitisation of the White Folder as such would overcome the students' lack of motivation in using it as well as the issue of connecting different contexts of learning. Therefore, this design idea was revised and the second iteration was called "Learning Toolbox". Rather than focusing on White Folder tasks directly, a light-weight framework was proposed for the management of commonly undertaken activities with the help of mobile devices. With the help of touch screen displays and large tiles the users can manage and share documents, record videos or audios and access online resources. The Learning Toolbox aims at adopting its contents to the context: This means that tools and information shall be displayed when they are relevant (e.g. special security instructions when work with a certain machine is necessary). One big advantage of this approach is that it is more flexible for incorporating digital materials for different tasks over a period of time, rather than being pressured to complete all the materials for any given task. Furthermore this approach should offer more flexibility in terms of linking informal and formal learning and learning in the training centres, in the vocational schools and in the workplace. Although this reorientation has taken place quite recently and the technical development of the Learning Toolbox is only reaching the phase of prototype, it has been possible to organise co-design workshops and other contact events to get feedback from apprentices and trainers as well as from company representatives.

Parallel to the development of those design ideas, training events to promote know-how on multimedia and web took place in the Bau-ABC. They addressed trainers and managers and in the first phase had a voluntarily basis. Topics addressed were e.g. video making and video annotation, augmented reality, working with Twitter and social bookmarking. The multimedia workshops also served the purpose of raising the users' awareness on possible technical solutions for their everyday's work and for their own capacity to contribute: whenever the trainers used a tool, they were encouraged to discuss how they could use it in practice. For example, videos were very interesting for many trainers and some of them soon started to let their apprentices make short videos on working processes. Here they saw, that they need a motion-sensitive camera (e.g. a GoPro, ideally as a helmet camera) in order to make good videos. The trainers also stated that videos 
could be used to introduce professional apprenticeship profiles to students (and also to companies, who not always know the exact definition of an occupational profile which they aim to offer). The Bau-ABC plans to use digital tools in projects with customers, e.g. to make a central public building site transparent to everyone who is interested by explaining what is happening (and maybe: who actually works there). The idea of using digital media is perceived as a possibility to attract new apprentices in the sector, but also as a perspective for new educational offerings.

Researchers and managers from the Bau-ABC also joined these multimedia workshops: some of them needed to learn how to use modern digital tools; on the other hand the question how trainers think about implementation settings of such tools became known to them. This experience had a healing disillusioning effect on both groups: the possibilities of new media were re-evaluated. It became clearer how learning in the Bau-ABC in the framework of a digitalised society could look like. This learning process was supported by a survey in which over 200 apprentices were asked which digital devices and which apps or software they use. One of the central insights here is that almost all apprentices in the Bau-ABC have a smart phone, but that they hardly use tablets. Although there are apps for the construction site available and known to the young people, most of them do not use them. For the apprentices, taking pictures as a form of work documentation is the central motive for using modern devices on the construction site. For the programming of Learning Layers tools this means that we should work with a smart phone-adaptable format and that we should offer learning invitations which are interwoven with tools that support work organisation (like photo connection). In some interviews, in addition, apprentices as well as craftsmen made clear that lack of knowledge is not the only or the most important barrier for accurate work: bad working conditions like the lack of time are also relevant factors. It is important to take this context variable into account e.g. when evaluations are aspired.

Although the use of many apps and web 2.0 software is not difficult, some trainers until now avoided working with them. Therefore the Bau-ABC is rethinking its strategy of volunteer participation in the multimedia workshops and plans to develop a training program in which (to lower the barriers) the more capable trainers train their colleagues. It is reflected which minimum requirements to the trainers' capabilities should be formulated. To support the multimedia workshops and to provide functionality for sharing ideas and learning materials, the project launched a social networking platform, BauBildung.net, based on Wordpress and Buddypress. The idea behind this is that only regular use of new media will prevent the trainers and managers from forgetting what they learned in the multimedia workshops. Since the equipment with digital media was not modern enough, a mobile set of tools was ordered which can be lent to each trainer who is interested in working with tablets, smart phones etc. During a multimedia workshop, nonetheless, the participants claimed that the exact policy how to use those tools is still not flexible enough to suit the idea of supporting situated learning via the use of digital devices. And another important discussion point occurred: In the workshops, the trainers were encouraged to register on Twitter, YouTube and other social platforms. Although the advantages of such networks seemed clear, this raised two very basic critical questions. The first is on work effort: if you have such an account, you need to take care for it, which can become very timeconsuming. On the other hand, the hunger for data of such networks can be regarded as a new threat for the work-life-balance: the support of the institute's image can lead to the problem that too much data is collected about the individuals 
promoting it (also as private persons). Therefore, the next internal discussions on the Bau-ABC will need to focus on finding a policy how to approach social networks.

The multimedia workshops developed the capacity of the organisation as a whole for creatively using technology for learning. At the same time the researchers had the opportunity to analyse how the growing awareness of emerging solutions makes it possible for the users to change their own working and learning culture. But also the researchers' attitudes towards digital media changed and became far more differentiated. Equally, the designers got new insights into key issues concerning the acceptability and possible benefits of the proposed solutions.

\subsection{Reflective commentary}

Below some key questions are formulated for an interactive research dialogue in which researchers, developers and users are challenged to find the turning points that help to overcome obstacles and to make the proposed solutions work in practice:

- How can potential users' attitudes to mobile technologies, web tools and apps/services be changed in the course of pilot activities? Is it possible to overcome mere leisure-time oriented consumerism and stimulate creative use of technologies to support working and learning?

- How can the use of such technologies, tools and apps/services help to bring the real working life closer to the learning situations in training centre? How can impulses and innovations be shared in such a way that they enrich working and learning culture?

- How can wider access to web resources be linked to better understanding on the usability and quality of web-based information? How can use of Internet and new media help the users to assess their own learning and professional growth (what they can do and what they can't)?

- How can improved access to information resources and media from different locations be utilised to make knowledge sharing across the organisation more effective (as support for working and learning)?

- How can easy possibilities to record and analyse learning experiences at work support professional development of individuals and knowledge sharing in organisations?

These questions reflect the character of the co-design activities as emerging innovations and the role of researchers as accompanying researchers. Also, the questions reflect the repositioning of research after a preparatory and observational phase to a more interactive and co-shaping phase. Therefore, the answers have to be found in the context of the participative process itself-using different participative events and complementary inquiries as sources of information. Thus, there have been several workshops with flexible intervals. These have shifted from conversational workshops (mapping issues) and storyboard workshops (mapping points of interventions) to more design-oriented workshops (feedback on possible solutions). At the same time there have been training events that mobilise apprentices and trainers as users and reviewers of apps, resources and e-learning models.

Until the end of the project, this path will be continued. It is important also for the researchers to stay involved because the most interesting effects of using digital media do not occur in the first contacts, but as long-term effects. We have good 
reasons to look positively to the future - nonetheless, taking into account critical research results on digital media (see e.g. Turkle, 2009; Bowers, 2014), we will keep our eyes open for problematic developments. From the perspective of contribution to theories, cooperation in the field gave some important hints which will be elaborated in respect to development tasks in professionalization and regarding the idea of co-design workshops as cradles of innovation.

\section{Conclusions: Dutch and German cases - similarities and differences}

Above we have discussed Dutch and German cases of interactive research as support for innovations in VET. At this point it is necessary to draw attention to the similarities and differences in the action contexts and in the institutional boundary conditions. Based on these analyses it is possible to draw some conclusions on the role of research as support for the development of innovations and in scaling them up.

\subsection{The institutional settings}

The Dutch case represents an innovation programme that promotes incorporation of work and work-related learning into school-based vocational education. Therefore, the institutional context is set up to legitimate work in practice and workrelated learning as extension of the school curriculum. In this context the task of the projects was to support the teaching staff to transform their practice and to accommodate new learning practices in education.

The German case is a pilot case from a major European research and development programme that focuses on promoting innovations in working life, in particular in SMEs and SME clusters. Therefore, the target area is to promote innovations in informal learning in craft trade companies and the role of the intermediate (industry-supported) training centre is that of a multiplier organisation. In this context the task of the interactive innovation project is to find ways how to develop the pilots launched in the training centre and to promote mechanisms that help to transfer innovations to SMEs in the construction sector.

\subsection{The project designs}

The Dutch project was shaped to support innovations in particular schools and in their immediate environments. The project has had a life cycle of four years. From the start a lot of effort was put into a script to promote particular innovation goals with a well-defined interactive project cycle. In this context interventions of researchers and the interaction with practitioners were clearly scheduled to support the jointly designed phases of the project cycle.

The German project was part of the work of a wider consortium that was designed to work together also for four years. Accordingly, the cooperation between research partners, technical developers and application partners was scripted as collaboration between work packages that were supported by consortium-wide integration measures during each year. In this context the local project work had more degrees of freedom to shape the local project dynamics by iterative development processes, co-design workshops and supporting training measures. 


\subsection{The innovation concepts as boundary-crossing practice}

In the Dutch project (and in the parallel projects) the innovation concept envisaged mainly intra-institutional rearrangements of working and learning activities in the so-called hybrid learning environment. In this context the challenge was a result of co-makership between school and regional business partners (re)designing the curricula.

In the German project the training centre was challenged to pilot new practices to incorporate Web 2.0 technologies - not merely to improve its own training practice but to serve as a competence centre and as a multiplier organisation vis-à-vis its partner enterprises and networks. In this respect the pioneers for innovative practice in training were preparing themselves to become promoters of such practices in their partner networks.

\subsection{Lessons learned}

The analysis above shows that the Dutch case and the German case have clearly different institutional backgrounds and innovation projects. These have to be taken into account as different realities. Yet, it is worthwhile to consider how the practices of interactive research on innovation can learn from each others' experiences.

\subsubsection{Project frameworks and their consequences}

In both cases the projects have tried to promote boundary-crossing practices but under different circumstances:

The Dutch project - and the parallel projects in the same programme have faced the challenge to work in tight schedules. In the hospitality case a routine was developed which can be described as a systematic PDCA-cycle which led to an innovative practice in action. In the building and construction case more stakeholders were involved. As a result - in spite of the good will of both researchers and practitioners - it was not possible to complete the project cycle as planned and to consolidate the innovative practice.

The German project - given the degrees of freedom enabled by the project description - had far more chances to find its track to an expansive innovation dynamics in which the prototyping with tools, internal pilots and training have paved the way towards outreach activities and promotion of innovation transfer. Even if the latter project has not yet reached its halftime milestone, it is appropriate to draw attention to the importance of the time factor and of the degrees of freedom regarding the reorientation and adjustment of the project work.

\subsubsection{Iterative and participative approach}

An important lesson to be drawn from both cases is the iterative approach. Both the Dutch and German project can be characterized by the use of an emergent research design: the projects did not work with detailed research plans for the whole period, but with recurrent phases of design, evaluation and revision. It is for this reason that such projects are often seen as chaotic. Next to creativity, a shared rule underlying educational design practice is the need to attune solutions to the context for which you design, meaning that specific conditions require specific interpretations of problems (Kirschner et al., 2002): what good is it, if you can't use it?

Finally, interactive research projects can be characterized as research from a naturalistic paradigm (Guba, 1981). Zitter (2010) describes three main elements 
that constitute this paradigm. First, in this paradigm it is assumed that there are multiple, interrelated realities, in which variables cannot be singled out for study or control. Second, this paradigm acknowledges that the inquirer and the respondents are interrelated, with each influencing the other. Third, this "paradigm rests on the assumption that generalisations are not possible, that at best what one can hope for [are] 'working hypotheses' that relate to a particular context” (Zitter, 2010, p. 144). Those 'working hypotheses', nonetheless, are deeply rooted in the researched environment and therefore relevant and valid; they need to be embedded into a broader scientific context but on the other hand they are important sources of scientific progress. To increase the quality of such research the following measures can be taken: the use of different methods, sources and approaches, prolonged engagement at a site and long-term observation, peer debriefing and reflexivity, member checks; the collection of thick descriptive data and the development of thick descriptions.

The data is collected and analysed by teams of researchers and in the Dutch case practitioner-researchers. Through team work the quality of the data collection and analysis can be increased through peer debriefing, reflexivity and member checks.

Successful implementation of the ideals of interactive research also requires that the research community is willing to employ the learning potential of the boundaries in these projects to critically review the contemporary research routines and methods. 


\section{References}

Akkerman, S.F., Bronckhorst, L.H. \& Zitter, I. (2013). The complexity of educational design research. Quality \& Quantity, 47(1), 421-439.

Akkerman, S.F. \& Bakker, A. (2011). Boundary crossing and boundary objects. Review of Educational Research, 81, 132-169.

Baartman, L.K.J., \& de Bruijn, E. (2011). Integrating knowledge, skills and attitudes: Conceptualizing learning processes towards vocational competence. Educational Research Review, 6, 125-134.

Billett, S. (2011). Curriculum and pedagogic bases for effectively integrating practice-based experiences - final report Strawberry Hills NSW, Australian learning and teaching council.

Bowers, C.A. (2014). The false promises of the digital revolution. How computers transform education, work and international development in ways that are ecologically unstable. New York: Peter Lang.

Burchert, J., Katterfeld, E., Schulte, S. \& Zeisig, A. (2013). Über die Kompetenzen und Motive der Nutzung des Internets in der Ausbildung. MERZ Zeitschrift für Medienpädagogik, 13/06, 97-107.

Burchert, J. (2010). Innovationsbereitschaft und Innovationsfähigkeit an beruflichen Schulen. ITB-Forschungsbericht Nr. 44, URL http://www.itb.unibremen.de/itb-forschungsberichte.html.

Deitmer, L. (2004). Management regionaler Innovationsnetzwerke. Bremen: Nomos.

Deitmer, L., Fischer, M., Gerds, P., Przygodda, K., Rauner, F., Ruch, H., Schwarzkopf, K. \& Zöller, A. (2004). Neue Lernkonzepte in der dualen Berufsausbildung. Bilanz eines Modellversuchsprogramms der Bund-Länder-Kommission (BLK). Bielefeld: Bertelsmann Verlag.

Ellström, P.-E. (2007). Knowledge Creation Through Interactive Research: A Learning Perspective. Paper presented at the HSS 07 Conference May 8-11 2007 (Universities and Society in collaboration). Jönköping University.

Ellström, P.E. (2008). Knowledge Creation Through Interactive Research: A Learning Approach. Paper presented at the ECER Conference, Gothenburg, September 10-12, 2008. University of Gothenborg.

Ellström, P.E. (2010). Practice-based innovation: a learning perspective. Journal of Workplace Learning, 22(1/2), 27-40.

Euler, D. \& Berger, K. (1999). Kooperation der Lernorte im dualen System der Berufsbildung. Materialien zur Berufsplanung und Forschungsförderung (73). Bonn: Bundesinstitut für Berufsbildung.

Fischer, M. (2000). Von der Arbeitserfahrung zum Arbeitsprozeßwissen: Rechnergestützte Facharbeit im Kontext beruflichen Lernens. Leske+ Budrich.

Fischer, M., Boreham, N. \& Nyhan, B. (2004). European perspectives on learning at work: the acquisition of work process knowledge. Luxembourg: Office for Official Publications for the European Communities.

Fischer, M., Jungeblut, R. \& Römmermann, E. (1995). „Jede Maschine hat ihre eigenen Marotten! “. Instandhaltungsarbeit in der rechnergestützten Produktion und Möglichkeiten technischer Unterstützung. Bremen.

Ferreira, B. (n.d.). Critical Moments Reflection Methodology. Mit.edu. URL: http://mit.edu/cil/web_scripts/www/Critical\%20Moments\%20Methodology\% 20Brief\%20CoLab.pdf. 
Guba, E. G. (1981). Criteria for Assessing the Trustworthiness of Naturalistic Inquiries. Educational Communication and Technology Journal, 29(2), 75-91.

Kirschner, P.A. (2005). Learning in Innovative Learning Environments. Computers in Human Behavior, 21, 547-554.

Nieuwenhuis, L., I. van der Neut, K. de Ries \& C. Teurlings (2012). Collective teacher learning through experimentation in VET. In: LLinE, Lifeling Learning in Europe, 17(4).

OECD (2013). Innovative Learning Environments, Educational Research and Innovation. OECD Publishing. doi: 10.1787/9789264203488-en.

Schaap, H., E. de Bruijn, M.F. Van der Schaaf L.K.J., Baartman. P.A. Kirschner (2011). Explicating Students' Personal Professional Theories in Vocational Education through Multi-method Triangulation. Scandinavian Journal of Educational Research, 55(6), 567-586.

Rauner, F. \& Maclean, R. (2008). Handbook of technical and vocational education and training research. Springer.

Rauner, F. \& Oehlke, P. (2008). Work and Technology Research. Handbook of Technical and Vocational Education and Training Research. Springer.

Sloane, P. (2008). Experimental Research Designs (ERD) in Vocational Education. In: Rauner, F. \& Maclean, R.: Handbook of Technical and Vocational Education and Training Research. Springer.

Stokols, D. (2006). Toward a Science of Transdisciplinary Action Research. In: American Journal of Community Psychology (38), 63-77.

Turkle, S. (2009). Interview Sherry Turkle. URL: http://www.pbs.org/wgbh/pages/ frontline/digitalnation/interviews/turkle.html.

Tynjälä, P., Välimaa, J. \& Sarja, A. (2003) Pedagogical perspectives on the relationships between higher education and working life. In: Higher Education, 46(2), 147-166.

Van Aken, J. \& Andriessen, D. (2011). Handboek ontwerpgericht wetenschappelijk onderzoek. [Handbook for Design Science Research]. Den Haag: Boom|Lemma.

Zitter, I. (2010). Designing for Designing for Learning. Studying learning environments in higher professional education from a design perspective. Published dissertation, Utrecht University.

Zitter, I. \& Hoeve, A. (2012). Hybrid Learning Environments: Merging Learning and Work Processes to Facilitate Knowledge Integration and Transitions. OECD Education Working Papers, No. 81, OECD Publishing. 